\title{
Characterization of Methyltransferase from Apramycin Biosynthetic Gene Cluster and Improvement Production of Apramycin in Engineered Streptoalloteichus Tenebrarius
}

\section{Junyang Sun (D 544729483@qq.com )}

Shenyang Pharmaceutical University https://orcid.org/0000-0002-0937-3300

\section{Hongjing Gao}

Shenyang Pharmaceutical University

\section{Danyang Yan}

Shenyang Pharmaceutical University

Yu Liu

Shenyang Pharmaceutical University

\section{Xianpu Ni}

Shenyang Pharmaceutical University

Huanzhang Xia

Shenyang Pharmaceutical University

\section{Research}

Keywords: Streptoalloteichus tenebrarius, apramycin biosynthesis pathway, aprl gene, methyltransferase

Posted Date: September 30th, 2021

DOI: https://doi.org/10.21203/rs.3.rs-927201/v1

License: (c) (i) This work is licensed under a Creative Commons Attribution 4.0 International License.

Read Full License 


\section{Abstract}

\section{Background}

Apramycin is a structurally unique aminoglycoside, used in veterinary medicine or the treatment of Salmonella, Escherichia coli and Pasteurella multocida infections in farm. Although discovered and used many years ago, many biosynthetic steps of apramycin are still obscure.

\section{Results}

In this study, we identified a HemK family methyltransferase, aprl, involved in apramycin biosynthesis. The function of aprl was studied by using gene disruption and biochemical experiments, and a new aminoglycoside antibiotic demethyl-apramycin was purified from apil disruption strain. Experiments proved that Aprl converted demethyl-aprosamine to aprosamine in vitro. Based on this, the apramycin production strain was improved by overexpression the Aprl to decrease the impurity production.

\section{Conclusions}

We have identified apd is a 7'-N-methyltransferase gene in apramycin biosynthesis and confirmed the substrate of methyltransferase. Engineering of aprl resulted in a strain producing a new aminoglycoside demethyl-apramycin and apramycin mono-producing strain with less impurity production. Finally, the yield of demethyl-apramycin in apramycin mono-producing strain decreased from $196 \pm 36 \mathrm{mg} / \mathrm{L}$ to $51 \pm 9$ $\mathrm{mg} / \mathrm{L}$, and the yield of apramycin increased from $2227 \pm 320 \mathrm{mg} / \mathrm{L}$ to $2331 \pm 210 \mathrm{mg} / \mathrm{L}$.

\section{Introduction}

Apramycin, produced by Streptoalloteichus tenebrarius, is a structurally unique aminoglycoside antibiotic. ${ }^{1}$ As frequently employed veterinary antibiotic drug, apramycin has the high antimicrobial activity on important gram-negative pathogens and has been mainly used for the treatment of Salmonella, Escherichia coli and Pasteurella multocida infections in poultry, swine or bovine..$^{2-3}$ Meanwhile, apramycin is a potent antibacterial with low ototoxicity, which properties distinct from all human used aminoglycosides. The properties attracted the attention of many research teams. ${ }^{4-5}$

Apramycin, carbamyltobramycin and carbamylkanamycin B are isolated from S. tenebrarius. ${ }^{6}$ They all belong to 2-dexoystreptomycin (2-DOS) aminoglycosides. Apramycin is characterized by 2-DOS linked with an unusual bicyclic 3'-deoxyoctose moiety. Carbamyltobramycin and carbamylkanamycin B are the 4, 6-disubstituted 2-DOS aminoglycoside antibiotic like gentamicin. Moreover, both carbamyltobramycin and carbamylkanamycin B (3-deoxy-carbamyltobramycin) share the same biosynthetic gene cluster (GenBank accession number: AJ810851). ${ }^{7}$ Apramycin has independent biosynthetic gene cluster (GenBank accession number: AJ629123) (Figure 1A). Base on bioinformatical analysis, the genes for the common intermediates 2-deoxystreptamine and paromamine can be easily identified both in apramycin and tobramycin biosynthetic gene clusters. ${ }^{8}$ Lividamine is the $3^{\prime}$ deoxygenated product of paromamine 
under the function of AprD3 and AprD4. ${ }^{9-12}$ Then, lividamine was oxidized by AprQ to form 6'-oxolividamine which may be the intermediate of bicyclic $3^{\prime}$-deoxyoctose moiety. ${ }^{13}$ Besides, it was confirmed that AprD3 and AprD4 are responsible for carbamyltobramycin 3'-deoxygenation process (Figure 1B). ${ }^{14}$ However, the biosynthetic pathway of the unique structure of apramycin is still obscure. Here, we report the identification and characterization of a 7'-N-methyltransferase gene, aprl, and its protein substrate, demethyl-aprosamine, involved in the conversion.

As other antibiotics, the accumulation of intermediate metabolites is also observed in apramycin fermentation products. The final apramycin products contain $0.9-2.7 \%$ of demethyl-apramycin. Therefore, demethyl-apramycin is one of the main impurity, its production should be controlled. Based on the study of the biosynthetic pathways of apramycin and tobramycin, we metabolic engineering $S$. tenebrarius to optimize apramycin production through block tobramycin biosynthesis and decrease impurity production.

\section{Results And Discussion}

Identify function of apd by gene deletion and complementation. Bioinformatically analyze the apramycin biosynthetic gene cluster showed that Aprl possessed homology with known methyltransferase, sharing a high degree of sequence identity with the N-methyltransferase CalM of Streptomyces chartreusis $(35 \%)^{18}$ and a lower degree of sequence identity with the 3"-N-methyltransferase GenN of Micromonospora echinospora (29\%). ${ }^{19}$ All of them belong to the HemK superfamily, which catalyzes methyl group transfer of a variety of substrates. Thus, we deduce Aprl is the 7'-N-methyltransferase in apramycin biosynthesis. To clarify this hypothesis, we carried out both genetic and biochemical analysis of Aprl in this work.

To clarify the function of aphl, aprl gene was disrupted in the wild-type strain of $S$. tenebrarius. PCR amplification with wild-type strain generated a $4.8 \mathrm{~kb}$ fragment, while the aprl mutant strain $(\Delta a p H)$ generated a $4.0 \mathrm{~kb}$ fragment because of a $789 \mathrm{bp}$ deletion (Figure $2 \mathrm{~A}$ and Figure 2B). The $4.0 \mathrm{~kb}$ fragment amplified from $\triangle a p r$ was further confirmed by DNA sequencing (data not shown). The results verified that aprl was successfully disrupted in $\Delta$ apr. The $\Delta$ aprl was cultured to analyze its fermented products. The wild-type strain of $S$. tenebrarius was used as control under the same fermentation conditions. Compared to the wild-type strain, the total antibiotic production in the $\Delta$ apt decreased from $2620 \mathrm{mg} / \mathrm{L}$ to $2183 \mathrm{mg} / \mathrm{L}$ (measured by bioassay). TLC coupled with an antimicrobial activity assay showed the $\Delta$ aprl produced a new bioactive product instead of apramycin (Figure 2C). HPLC analysis confirmed that $\Delta$ aprl accumulated a new compound 2 (Figure 2D). By HRMS analysis, the new component 2 produced by $\Delta$ aprl was considered as demethyl-apramycin (Figure S1). The demethyl product was also analyzed by MS/MS (Figure S1). The protonated fragments were similar to those of the reported mass spectra of apramycin, however, the glycoside bond of this compound cleavage formed the fragment $a+b(\mathrm{~m} / z 365)$ instead of the ion at $m / z 379,{ }^{20}$ suggesting the demethyl-apramycin might lack a methyl group at 7'-N. 2 then was purified from the fermentation broth of $\Delta a p r$. The ${ }^{13} \mathrm{C}-\mathrm{NMR}$ analysis definitively confirmed that compound 2 lacked a 7'-N-methyl group (Figure S2 and Table S4). To preclude any possible of polar 
effects, we performed $\Delta$ aph complementary. The aphl complementary plasmid pAP605, in which the entire aprl gene is under the control of the PhrdB promotor, was introduced by intergenic conjugation into $\Delta a p h$. We screened for the erythromycin-resistance phenotype to isolate the apt complementary strain, and we designated this strain as $\triangle a p r:: a p r$. HPLC analysis showed that the $\Delta$ aprl::aprl restored the ability to produce apramycin (Figure 2D). Thus, the possibility that aprl gene disruption had other polar effects can be ruled out. These results illustrate that Aprl was the 7'-N-methyltransferase in apramycin biosynthesis.

David Crich utilized chemical synthesis methods to prepare a series of apramycin derivatives, and investigated their antibacterial activity. In these derivatives, demethyl-apramycin had good activity against E.coli and Staphylococcus aureus, and was as good as apramycin in some cases. ${ }^{21}$ As the main product of $\Delta$ aprl strain is demethyl-apramycin, this strain provide a convenience, efficient and continuable method for production the potentially valuable aminoglycoside antibiotic demethylapramycin.

Catalytic specificity of Aprl. An in vivo gene disruption experiment demonstrated that the aprl gene is involved in the unique methylation process of apramycin synthesis. However, the methylation substrate and mechanism are still unknown. Thus, aprl was cloned into the expression vector pET28a(+), and recombinant Aprl was expressed as an N-terminal $\mathrm{His}_{6}$-tagged protein and expressed in E. coli BL21 as described in Methods. It is composed of 262 amino acids and is predicted to have a molecular weight of 28.8 KDa. After separation and purification on a nickel column, the molecular size was determined by SDS-PAGE to be consistent with the molecular weight of Aprl (Figure 3A).

Recombinant Aprl was assayed for the ability to catalyze the SAM-dependent methyl transfer reaction which convert demethyl-apramycin to apramycin. However, this recombinant protein was not able to catalyze this reaction (Figure $3 \mathrm{C}$ ). Thus, it was speculated that the $7^{\prime}-\mathrm{N}$ methylation of apramycin may occur at the pseudo-trisaccharide instead of the pseudo-tetrasaccharide. We then attempted to hydrolyze demethyl-apramycin to prepare the proper substrate. ${ }^{22}$ We identified the product by HPLC and MS and named it demethyl-aprosamine (Figure S3). Using demethyl-aprosamine as substrate, the catalysis results showed that demethyl-aprosamine was converted into a new compound under the presence of both Aprl and SAM (Figure 3B). It is worth noting that the reaction product showed two peaks in the HPLC analysis. As the two peaks cannot be isolated, we speculated that the two peaks might be mutually convertible isomers. To prepare the authentic aprosamine for HPLC analysis of Aprl enzymatic reaction, apramycin was hydrolyzed. Furthermore, its hydrolysate also showed two peaks is identical with Aprl catalytic product in the HPLC analysis (data not shown). Therefore, the two new Aprl catalyzed products together were deduced as aprosamine and its isomer (Figure S4 and Figure S5). These results confirm that Aprl catalyze pseudo-trisaccharide methylation rather than pseudo-tetrasaccharide (Figure 3D).

Methyl groups have stereoelectronic effects on micromolecules and biomacromolecules, thereby leading to a diversity of biological effects, containing the selectivity between biological receptors, increased potency, and protection against enzyme metabolism. ${ }^{23}$ Methyltransferases in the biosynthesis of 
aminoglycoside antibiotics are mainly divided into two types. The first type is using SAM as a methyl donor to catalyze the methylation of the substrate. And the other is radical SAM enzyme catalyzing nonuniversal methylation. In the biosynthesis pathway of the aminoglycoside antibiotic gentamicin, there are four methyltransferases, including GenK, GenD1, GenN, and GenL. ${ }^{24}$ GenK and GenD1 were identified as cobalamin-dependent radical SAM methyltransferases that transfer the methyl group to the carbon atom at the position of C6' $^{\prime}$ and C4" in gentamicin biosynthesis, respectively. They have a common [4Fe-4S] cluster and a highly conserved "CXXXCXXC" motif in their active sites. The two radical SAM enzymes are reported to extract a hydrogen atom from the corresponding sites of their substrates to provide a radical intermediate utilizing 5'-dAdo originating from SAM. The radical intermediate forms a C-C bond with the methyl group on methylcobalamin to obtain the C-methylated product. ${ }^{25-26} \mathrm{GenL}$ as the $6^{\prime}-\mathrm{N}$ methyltranserase and GenN as the 3 "-N-methyltranserase in gentamicin are classified in class I SAMdependent methyltransferase. As the terminal 6'-N-methyltrasferase, GenL has the activicity in the conversion of both $\mathrm{C} 2$ to $\mathrm{C} 1$ and of $\mathrm{C} 1 \mathrm{a}$ to $\mathrm{C} 2 \mathrm{~b}$. But $\mathrm{GenL}$ is an enzyme with low sequence similarity to GenN and other N-methyltransferases, reaction mechanism of GenL still unknown. ${ }^{24}$ Similar to Aprl, GenN belongs to the HemK family, which has relatively conserved "GXGXG" and "NSPT" sites to interact with $\mathrm{SAH}$. The protein crystal structure of GenN has been determined. ${ }^{27}$ Different from Aprl, GenN can catalyze multiple pseudo-trisaccharide substrates, containing A1, A-2, Ae, and A. However, Aprl act on 7'-N of the demethyl-aprosamine in this study. As a unique site methyltransferase in the biosynthesis of aminoglycoside antibiotics, substrate scopes and reaction mechanisms of Aprl deserve further study and its research will provide a basis for the development of new aminoglycoside antibiotics.

\section{Overexpression of aph by homologous recombination in $S$. tenebrarius reduced demethyl-apramycin as an impurity in apramycin production.}

Promoter engineering and gene knockout are the most direct and effective metabolic engineering methods for changing metabolic flow. Industrial production of apramycin is performed by microbial fermentation. Our final products contain $0.9-2.7 \%$ of demethyl-apramycin, which is the major impurity in apramycin biosynthesis. However, there is only a methyl group difference between demethyl-apramycin and apramycin, it is pretty difficult to separate demethyl-apramycin and apramycin in production process. To reduce the production of demethyl-apramycin by metabolic engineering, we intended to increase the expression of aprl. To elevate the genetic stability of engineering strains, we integrated aprl into the chromosome via homologous recombination rather than site-specific integration.

Because $S$. tenebrarius produce apramycin and tobramycin simultaneously, disruption tobramycin biosynthetic pathway not only can eliminate the impurity tobramycin from apramycin, but also tuned the shared biosynthetic precursors to apramycin biosynthesis. We attempted to insert the apr gene in the tobramycin biosynthesis gene cluster to obtain strain for apramycin mono-production. In tobramycin biosynthesis gene cluster of $S$. tenebrarius, the tobM2 gene was considered as the second glycosyltransferase, converting the intermediate nebramine to tobramycin (Figure 1B). ${ }^{14}$ To confirm tobM2 gene was unrelated to apramycin biosynthesis, the tobM2 gene was disrupted in the wild-type 
strain of $S$. tenebrarius. The tobM2 deletion plasmid pAP600 was introduced into $S$. tenebrarius by conjugation transfer to obtain the tobM2-disruption strain via the double crossover homologous recombination event. The PCR and DNA sequencing results confirmed that the selected strain designated $\Delta t o b \mathrm{M} 2$ does not possess the $1263 \mathrm{bp} t o b \mathrm{M} 2$ sequence. The $\Delta t o b \mathrm{M} 2$ was later cultured to analyze its fermented biosynthetic products. HPLC analysis confirmed that $\Delta$ tobM2 strain still produced apramycin and did not produce tobramycin (Figure S6).

Next, aprl which are under the control of PhrdB, was inserted into the homology arm of tobM2 via homologous recombination (Figure 4A and Figure 4B). The overexpressing strain was named $S$. tenebrarius IB. HPLC assays demonstrated that the demethyl-apramycin yield decreased from $196 \pm 36$ $\mathrm{mg} / \mathrm{L}$ to $51 \pm 9 \mathrm{mg} / \mathrm{L}$ and that the percentage of demethyl-apramycin among the total apramycin products decreased from $1.17 \%$ to $0.34 \%$. The apramycin yield of the wild-type strain was $2227 \pm 320 \mathrm{mg} / \mathrm{L}$ and that of $S$. tenebrarius IB was $2331 \pm 210 \mathrm{mg} / \mathrm{L}$ (Figure 4C). Through overexpression aprl, demethylapramycin yield was further decreased, and the purity of apramycin in the fermentation products was improved. Moreover, the tobramycin yield of the wild-type strain was $607 \pm 111 \mathrm{mg} / \mathrm{L}$ and that of $S$. tenebrarius IB was no more producing (Figure 4C).

In the process of constructing aprl overexpressing strain, we attempted to obtain the anticipated strain using site-specific integration plasmid pAP605. However, previousresearch had suggested that successive passages of strains lead to elimination of the site-specific integration plasmid. ${ }^{15} \mathrm{We}$ compared the site-specific integration and the homologous recombination by comparing the products through five passages. The homologous recombination strain had better stability compared with the sitespecific integration strain, and the production of $S$. tenebrarius IB is not affected by the passages (data not shown).

\section{Conclusions}

Aprl was identified as 7'-N methyltransferase in apramycin biosynthesis by gene disruption and biochemical study. Aprl had an activity to transfer a methyl group at the position of 7'-N of demethylaprosamine. By deletion the aprl gene, an aminoglycoside antibiotic demethyl-apramycin high producing strain was constructed. Base on the study of apramycin biosynthetic pathway and tobramycin biosynthetic pathway in $S$. tenebrarius, the strain overexpression of apt was constructed to decrease the impurity production of demethyl-apramycin and tobramycin. The content of demethyl-apramycin in the aprl overexpression strain was reduced from $196 \pm 36 \mathrm{mg} / \mathrm{L}$ to $51 \pm 9 \mathrm{mg} / \mathrm{L}$. And apramycin in the apr overexpression strain was increased from $2227 \pm 320 \mathrm{mg} / \mathrm{L}$ to $2331 \pm 210 \mathrm{mg} / \mathrm{L}$. The tobramycin yield of the wild-type strain was $607 \pm 111 \mathrm{mg} / \mathrm{L}$ and that of aprl overexpression strain was no more producing.

\section{Materials And Methods}

Strains and growth conditions. The plasmids used in this study are listed in Table S1. The strains used in this study are listed in Table S2. E. coli Top10 was used as cloning host, E. coli ET12567/pUZ8002 for 
intergeneric conjunction between E. coli and Streptomyces, and E. coli BL21 (DE3) was used for protein expression experiments. Wild-type Streptoalloteichus tenebrarius and its mutants were grown on agar medium $\left(20 \mathrm{~g} / \mathrm{L}\right.$ soluble starch, $1 \mathrm{~g} / \mathrm{L}$ beef extract, $1 \mathrm{~g} / \mathrm{L} \mathrm{KNO}_{3}, 0.5 \mathrm{~g} / \mathrm{L} \mathrm{K}_{2} \mathrm{HPO}_{4} \cdot 3 \mathrm{H}_{2} \mathrm{O}, 0.5 \mathrm{~g} / \mathrm{L} \mathrm{NaCl}, 0.5$ $\mathrm{g} / \mathrm{L} \mathrm{MgSO}{ }_{4} \cdot 7 \mathrm{H}_{2} \mathrm{O}, 0.01 \mathrm{~g} / \mathrm{L} \mathrm{FeSO}_{4} \cdot 7 \mathrm{H}_{2} \mathrm{O}, 15 \mathrm{~g} / \mathrm{L}$ agar, $\left.\mathrm{pH} 7.2\right)$ for sporulation and liquid $\mathrm{CP}(20 \mathrm{~g} / \mathrm{L}$ glucose, $2 \mathrm{~g} / \mathrm{L}$ peptone, $4 \mathrm{~g} / \mathrm{L}$ yeast extract, $0.5 \mathrm{~g} / \mathrm{L} \mathrm{MgSO}{ }_{4} \cdot 7 \mathrm{H}_{2} \mathrm{O}, 0.5 \mathrm{~g} / \mathrm{L} \mathrm{K}_{2} \mathrm{HPO}_{4} \cdot 3 \mathrm{H}_{2} \mathrm{O}, 0.5 \mathrm{~g} / \mathrm{L} \mathrm{NaCl}$ ) for mycelium. $S$. tenebrarius and its derivative mutants were cultured in the seed medium $(10 \mathrm{~g} / \mathrm{L}$ soyal bean, $10 \mathrm{~g} / \mathrm{L}$ glucose, $3 \mathrm{~g} / \mathrm{L}$ peptone, $1 \mathrm{~g} / \mathrm{L}$ yeast powder, $5 \mathrm{~g} / \mathrm{L}$ corn powder, $1 \mathrm{~g} / \mathrm{L} \mathrm{CaCO}{ }_{3}$ ) at $37^{\circ} \mathrm{C}$ for 18 hours, $3 \mathrm{~mL}(10 \%[\mathrm{v} / \mathrm{v}])$ seed culture was used to inoculate the fermentation medium $(40 \mathrm{~g} / \mathrm{L}$ soyal bean, $20 \mathrm{~g} / \mathrm{L}$ glucose, $20 \mathrm{~g} / \mathrm{L}$ soluble starch, $5 \mathrm{~g} / \mathrm{L}$ yeast powder, $5 \mathrm{~g} / \mathrm{L} \mathrm{CaCO}_{3}$ (light), $5 \mathrm{~g} / \mathrm{L} \mathrm{NH}_{4} \mathrm{Cl}, 2 \mathrm{~g} / \mathrm{L} \mathrm{MgSO}_{4}, 0.05$ $\mathrm{g} / \mathrm{L} \mathrm{FeSO}_{4}, 0.03 \mathrm{~g} / \mathrm{L} \mathrm{ZnSO}_{4}, 0.3 \mathrm{~g} / \mathrm{L} \mathrm{MnCl}_{2}$ ) and was incubated for 5 days. E. coli strains were maintained in Luria-Bertani (LB) liquid or solid medium ( $10 \mathrm{~g} / \mathrm{L}$ yeast extract, $5 \mathrm{~g} / \mathrm{L}$ tryptone, $10 \mathrm{~g} / \mathrm{L} \mathrm{NaCl})$ at $37^{\circ} \mathrm{C}$ with appropriate antibiotic selection at final concentration of $100 \mu \mathrm{g} / \mathrm{mL}$ ampicillin, $25 \mu \mathrm{g} / \mathrm{mL}$ chloramphenicol, and $50 \mu \mathrm{g} / \mathrm{mL}$ kanamycin.

Construction of the tobM2-disruption plasmids. Base on the sequence of the tobramycin biosynthetic gene cluster above, two DNA fragments flanking tobM2 were amplified from the genomic DNA of $S$. tenebrarius ${ }^{15}$ by using M2U-P1/P2 and M2D-P3/P4. The PCR products were fusion and cloned into pMD18-T (Takara), and verified by restriction endonuclease digestion and sequencing. The fragment was cloned into pSPU310 to obtain the gene disruption plasmid pAP600.

Construction of the aprl-disruption plasmids. The sequence of the apramycin biosynthetic gene cluster has been deposited in the NCBI under the accession number GenBank AJ629123. For deletion of the apramycin biosynthesis gene aprl, two DNA fragments flanking aprl were amplified from the genomic DNA of S. tenebrarius by using IU-P1/P2 and ID-P3/P4. The PCR products were cloned into pIJ2925 to obtain plasmid pAP601, which was verified by restriction endonuclease digestion and sequencing. Then, the homogenous arm of aprl was cloned into pSPU310 to obtain the gene disruption plasmid pAP602.

Targeted gene deletion. To create double-cross deletion mutants $\triangle t o b \mathrm{M} 2$ and $\Delta a p r l$ based on wild-type strain S. tenebrarius, the corresponding plasmids pAP600 and pAP602 were introduced into S. tenebrarius by conjugation, respectively, and mutants screening were carried out using the same method described before. ${ }^{7}$ The desired deletion mutants were identified by PCR using the checking primers.

Complementation of $\Delta$ apd mutant strain. For complementation of the aprl gene mutant, pAP603 was constructed as the intermediate vector by inserting aprl into pHJK241 $1^{16}$ between the Ncol and HindIII sites. Then pAP605 was constructed by inserting apd into the vector pEAP1 ${ }^{17}$ under the control of the constitutive promoter PhrdB. The plasmid pAP605 was then introduced into $\triangle a p H$ by conjugation. Complemented exconjugants were verified on agar medium containing erythromycin $(100 \mu \mathrm{g} / \mathrm{mL})$ and confirmed by PCR.

Construction of the apH overexpressing strain based on homologous recombination. The fragment of PhrdB, aprl and T0 was digested from pAP603 by Bg/l, and then was added to plasmid pAP600 to 
obtain the recombinated plasmid pAP607. Plasmid pAP607 was introduced into $S$. tenebrarius by conjugation using the method described before. Targeted strain named $S$. tenebrarius IB was confirmed by PCR.

Extraction, and analysis of apramycin. Oxalic acid was added to the fermentation broths in order to precipitate calcium and magnesium ions. The $\mathrm{pH}$ was adjusted to 2.0 with $\mathrm{H}_{2} \mathrm{SO}_{4}$ and agitated for 1 hour. The acidified broth was centrifuged at $7000 \mathrm{r} / \mathrm{min}$ for 10 minutes, and the $\mathrm{pH}$ of the supernatant was readjusted to 9.0 with $\mathrm{NH}_{4} \mathrm{OH}$. This pretreated supernatant was then centrifuged at $7000 \mathrm{r} / \mathrm{min}$ for 10 minutes. The supernatant was readjusted to $\mathrm{pH} 5.5$ with $\mathrm{H}_{2} \mathrm{SO}_{4}$, applied onto a strongly acidic resin $001 \times 7$ (Anhui Sanxing Resin Technology), and then the bound substances were eluted with $2 \mathrm{~mol} / \mathrm{L}$ $\mathrm{NH}_{4} \mathrm{OH}$. The eluate was used for bioassays and thin-layer chromatography analysis (TLC). Propanolmethanol-25\% ammonium hydroxide (20:25:23) was used for the solvent system of TLC. The bioassay was performed with Bacillus subtilis by via agar diffusion. Reversed-phase high-performance liquid chromatography (RP-HPLC) was performed using a LC-10AT system with an evaporative light scattering detector (ELSD). Reverse $\mathrm{C}_{18}$ column $(4.6250 \mathrm{~mm}, 5 \mu \mathrm{m})$ was utilized with an evaporation temperature of $45^{\circ} \mathrm{C}$, a nitrogen pressure of $3.5 \mathrm{bar}$, and $0.2 \mathrm{~mol} / \mathrm{L}$ trifluoroacetic acid as the running water. ${ }^{1} \mathrm{H}$ and ${ }^{13} \mathrm{C}$ nuclear magnetic resonance (NMR) data were recorded on a Bruker AV600 at a frequency of $600 \mathrm{MHz}$ using $\mathrm{D}_{2} \mathrm{O}$ as the solvent. High-resolution ESI-MS was performed by Department of Experiment Center at Shenyang Pharmaceutical University.

Expression and purification of Aprl. The aph gene was amplified from the genomic DNA of S. tenebrarius genomic DNA by PCR using pfu polymerase (BBI) and the oligonucleotides (Takara). The PCR product was purified by gel extraction, and inserted into vector pET-28a (+) between the Ndel and EcoRI sites to create pAP606. The resulting construct was verified by DNA sequencing, then used to transform $E$. coli BL21(DE3) cells using the heat-shock method. BL21(DE3)/pAP606 cells were grown in $3 \mathrm{~mL} L B$ medium containing kanamycin $(50 \mathrm{mg} / \mathrm{mL})$ at $37^{\circ} \mathrm{C}$ until an optical density $(600 \mathrm{~nm})$ of $0.6-0.8$ was achieved, then the cultures induced by isopropylthiogalactoside $(0.5 \mathrm{mM})$ at $16^{\circ} \mathrm{C}$ with shaking overnight. For purification, the cell pellets from $2 \mathrm{~L}$ culture were harvested by centrifugation at $7000 \mathrm{r} / \mathrm{min}$ for 15 minutes, and resuspended in $20 \mathrm{~mL}$ of binding buffer $(20 \mathrm{mmol} / \mathrm{L}$ tris- $\mathrm{HCL}, 0.5 \mathrm{~mol} / \mathrm{L} \mathrm{NaCl}, 5 \mathrm{mmol} / \mathrm{L}$ imidazole, $\mathrm{pH}$ 8.0), and then opened through ultrasonication for 30 minutes on ice. Supernatant was separated from cell debris by centrifugation at $12000 \mathrm{r} / \mathrm{min}$ for 40 minutes at $4^{\circ} \mathrm{C}$ and passed through a 1 $\mathrm{mL}$ IMAC column (GE Healthcare) charged with nickel and previously equilibrated with binding buffer. After washing the column with $30 \mathrm{~mL}$ of binding buffer followed by $10 \mathrm{~mL}$ of wash buffer $(20 \mathrm{mmol} / \mathrm{L}$ tris-HCL, $0.5 \mathrm{~mol} / \mathrm{L} \mathrm{NaCl}, 40 \mathrm{mmol} / \mathrm{L}$ imidazole, $\mathrm{pH} \mathrm{8.0)}$ ), the protein was eluted with elution buffer (20 $\mathrm{mmol} / \mathrm{L}$ tris-HCL, $0.5 \mathrm{~mol} / \mathrm{L} \mathrm{NaCl}, 200 \mathrm{mmol} / \mathrm{L}$ imidazole, $\mathrm{pH}$ 8.0). Fractions involving the desired product were collected and dialyzed (10 mmol/L tris-HCL, $250 \mathrm{mmol} / \mathrm{L} \mathrm{NaCl}, 10 \%$ glycerol, $\mathrm{pH}$ 8.0). Protein was concentrated to $13 \mathrm{mg} / \mathrm{mL}$ and stored in $10 \%$ glycerol at $-20^{\circ} \mathrm{C}$ until used.

Enzymatic assay of Aprl. The in vitro enzymatic assay of Aprl was performed by combining $17 \mathrm{mmol} / \mathrm{L}$ $\mathrm{K}_{2} \mathrm{HPO}_{4} / \mathrm{KH}_{2} \mathrm{PO}_{4}(\mathrm{pH} 7.4), 2 \mathrm{mmol} / \mathrm{L}$ S-adenosylmethionine (SAM), $0.4 \mathrm{mM}$ substrate, and $10 \mu \mathrm{mol} / \mathrm{L}$ 
purified recombinant $\mathrm{Aprl}$ in a $500 \mu \mathrm{L}$ total reaction volume. The reaction was incubated at $30^{\circ} \mathrm{C}$ and then stopped by the addition of $1 \mathrm{x}$ volume of chloroform, followed by vigorous vortexing to denature the proteins. The mixture was centrifuged at 10,000 r/min for 5 minutes, and the supernatant was subjected to HPLC-ELSD and MS analysis.

\section{Abbreviations}

2-DOS: 2-dexoystreptomycin

SAM: S-adenosylmethionine

TLC: Thin-layer chromatography analysis

HPLC: High-performance liquid chromatography

ELSD: Evaporative light scattering detector

NMR: Nuclear magnetic resonance

\section{Declarations}

\section{Availability of data and materials}

The data that support the findings of this study are available from the corresponding author, upon request.

\section{Acknowledgments}

Not applicable.

\section{Funding}

This work was supported by the Scientific Research Fund of Liaoning Provincial Education Department (2017LZD05, 2019LZD03).

\section{Author information}

Affiliations

School of Life Science and Biopharmaceutics, Shenyang Pharmaceutical University, No.103 Wenhua Road, Shenyang, Liaoning, China

Junyang Sun, Hongjing Gao, Danyang Yan, Yu Liu, Xianpu Ni and Huanzhang Xia Authors Contributions 
J. S., H. G., X. N., and H. X. conceived the experiments; and J. S. constructed and analyzed mutants; J.S. carried out in vitro analysis; J. S., H. G., Y. L., D. Y., X. N., and H. X. analyzed the results; and H. X., X. N., and J. S. wrote the paper.

Corresponding author

Correspondence to Huanzhang Xia and Xianpu Ni.

\section{Ethics declarations}

Ethics approval and consent to participate

Not applicable.

Consent for publication

Not applicable.

\section{Competing interests}

The authors declare no competing interests.

\section{References}

1. Tamura T., Ishida Y., Otoguro M., Hatano K., Suzuki K. (2008). Classification of 'Streptomyces tenebrarius' Higgins and Kastner as Streptoalloteichus tenebrarius nom. rev. comb. nov. and emended description of the genus Streptoalloteichus. Int. J. Syst. Evol. Microbiol., 58., 688-91. https://doi.org/10.1099/ijs.0.65272-0

2. Zhang X., Ding L., Fan M. (2009). Resistance patterns and detection of aac(3)-IV gene in apramycinresistant Escherichia coli isolated from farm animals and farm workers in northeastern of China. Res. Vet. Sci., 87, 449-454. https://doi.org/10.1016/j.rvsc.2009.05.006

3. Ziv G., Bor A., Sobagk S., ELAD D., Nouws J. K. M. (2010). Clinical pharmacology of apramycin in calves. J. Vet. Pharmacol. Ther., 8, 95-104. https://doi.org/10.1111/j.1365-2885.1985.tb00930.x

4. Matt T., Ng C. L., Lang K., Sha S., Akbergenov R., Shcherbakov D., Meyer M., Duscha S., Xie J., Dubbaka S. R. (2012). Dissociation of antibacterial activity and aminoglycoside ototoxicity in the 4monosubstituted 2-deoxystreptamine apramycin. Proc. Natl. Acad. Sci. U. S. A., 109, 1098410989. https://doi.org/10.1073/pnas.1204073109.

5. Becker K., Aranzana-Climent V., Cao S., Nilsson A., Shariatgorji R., Haldimann K., Platzack B., Hughes D., Andrén P. E., Böttger E. C. (2020). Efficacy of EBL-1003 (apramycin) against Acinetobacter baumannii lung infections in mice. Clin. Microbiol. Infect., 27, 1315-1321.

https://doi.org/10.1016/j.cmi.2020.12.004 
6. Koch K. F., Davis F. A., Rhoades J. A. (1973). Nebramycin: separation of the complex and identification of factors 4, 5, and 5". J. Antibiot., 26, 745-751. https://doi.org/10.7164/antibiotics.26.745

7. Ni X., Li D., Yang L., Huang T., Li H. Xia H. (2011). Construction of kanamycin B overproducing strain by genetic engineering of Streptomyces tenebrarius. Appl. Microbiol. Biotechnol., 89, 723-731. https://doi.org/10.1007/s00253-010-2908-5.

8. Kudo F. (2020). Biosynthesis of aminoglycoside antibiotics. Comprehensive Natural Products III: Chemistry and Biology. 2, 588-612. https://doi.org/10.1016/B978-0-12-409547-2.14619-0

9. Kim H. J., LeVieux J., Yeh Y., Liu H. (2016). C3'-Deoxygenation of paromamine catalyzed by a radical S adenosylmethionine enzyme: characterization of the enzyme AprD4 and its reductase partner AprD3. Angew. Chem., Int. Ed., 128, 3788-3792. https://doi.org/10.1002/anie.201510635.

10. Kudo F., Tokumitsu T., Eguchi T. (2016). Substrate specificity of radical S-adenosyl-I-methionine dehydratase AprD4 and its partner reductase AprD3 in the C3'-deoxygenation of aminoglycoside antibiotics. J Antibiot., 70, 423-428. https://doi.org/10.1038/ja.2016.110.

11. Lv M., Ji X., Zhao J., Li Y., Zhang C., Su L., Ding W., Deng Z., Yu Y., Zhang Q. (2016). Characterization of a C3 deoxygenation pathway reveals a key branch point in aminoglycoside biosynthesis. J. Am. Chem. Soc., 138, 6427-6435. https://doi.org/10.1021/jacs.6b02221.

12. Liu W., Amara P., Mouesca J., Ji X., Renoux O., Martin L., Zhang C., Zhang Q., Nicolet Y. (2018). 1,2-diol dehydration by the radical SAM enzyme AprD4: a matter of proton circulation and substrate flexibility. J. Am. Chem. Soc., 140, 1365-1371. https://doi.org/10.1021/jacs.7b10501.

13. Wang J., Ma S., Ding W., Chen T., Zhang Q. (2021). Mechanistic study of the oxidoreductase AprQ involved in the biosynthesis of the aminoglycoside antibiotic apramycin. Chin. J. Chem., 39, 1923-1926. https://doi.org/10.1002/cjoc.202100070

14. Park J., Park S., Nepal K., Han A., Ban Y., Yoo1 Y., Kim E., Kim E., Kim D., Sohng J., Yoon Y. (2011). Discovery of parallel pathways of kanamycin biosynthesis allows antibiotic manipulation. Nat. Chem. Biol., 7, 843-852. https://doi.org/10.1038/nchembio.671

15. Du Y., Li T., Wang Y., Xia H. (2004). Identification and functional analysis of dTDP-Glucose-4,6dehydratase gene and its linked gene cluster in an aminoglycoside antibiotics producer of Streptomyces tenebrarius H6. Curr. Microbiol., 49, 99-107. https://doi.org/10.1007/s00284-004-4212-z.

16. Gao W., Wu Z., Sun J., Ni X., Xia H. (2017). Modulation of kanamycin B and kanamycin A biosynthesis in Streptomyces kanamyceticus via metabolic engineering. PLoS ONE., 12, e0181971. https://doi.org/10.1371/journal.pone. 0181971.

17. Gu Y., Ni X., Ren J., Gao H., Wang D., Xia H. (2015). Biosynthesis of epimers C2 and C2a in the gentamicin C complex. ChemBioChem., 16, 1933-1942. https://doi.org/10.1002/cbic.201500258 
18. Wu Q., Gou L., Lin S., Liang J., Yin J., Zhou X., Bai L., An D., Deng Z., Wang Z. (2013). Characterization of the N-methyltransferase CalM involved in calcimycin biosynthesis by Streptomyces chartreusis NRRL 3882. Biochimie, 95, 1487-1493. https://doi.org/10.1016/j.biochi.2013.03.014

19. Ni X., Zong T., Zhang H., Gu Y.; Huang M., Tian W., Xia H. (2016). Biosynthesis of 3"-demethylgentamicin $\mathrm{C}$ components by gen $\mathrm{N}$ disruption strain of Micromonospora echinospora and test their antimicrobial activities in vitro. Microbiol. Res., 185, 36-44.

https://doi.org/10.1016/j.micres.2016.01.005.

20. Park J. W., Park S. R., Han A. R., Ban Y. H., Yoo Y. J., Kim E. J., Yoon Y. J. (2010). The nebramycin aminoglycoside profiles of Streptomyces tenebrarius and their characterization using an integrated liquid chromatography-electrospray ionization-tandem mass spectrometric analysis. Anal. Chim. Acta., 661, 76-84. https://doi.org/10.1016/j.aca.2009.12.014.

21. Mandhapati A. R., Shcherbakov D., Duscha S., Vasella A., Böttger E. C., Crich D. (2014). Importance of the 6'-hydroxy group and its configuration for apramycin activity. ChemMedChem., 9, 20742083. https://doi.org/10.1002/cmdc.201402146

22. O'Connor S., Lam L. K. T., Jones N. D., Chaney M. O. (1976). Apramycin, a unique aminocyclitol antibiotic. J. Org. Chem., 7, 2087-2092. https://doi.org/10.1021/jo00874a003

23. Barreiro E. J., Kümmerle A. E., Fraga C. A. M. (2011). The methylation effect in medicinal chemistry. Chem. Rev., 111, 5215-5246. https://doi.org/10.1021/cr200060g

24. Li S., Guo J., Reva A., Huang F., Xiong B., Liu Y., Deng Z., Leadlay P. F., Sun Y. (2018). Methyltransferases of gentamicin biosynthesis. Proc. Natl. Acad. Sci. U. S. A., 155, 13401345. http://dx.doi.org/10.1073/pnas.1711603115.

25. Kim H. J., McCarty R. M., Ogasawara Y., Liu Y., Mansoorabadi S. O., Vieux J. L., Liu H. (2013). GenKcatalyzed C-6' methylation in the biosynthesis of gentamicin: isolation and characterization of a cobalamin-dependent radical SAM enzyme. J. Am. Chem. Soc., 135, 8093-8096.

https://doi.org/10.1021/ja312641f

26. Huang C., Huang F., Moison E., Guo J., Jian X., Duan X., Deng Z., Leadlay P. F., Sun Y. (2015). Delineating the Biosynthesis of Gentamicn X2, the Common Precursor of the Gentamicin C Antibiotic Complex. Chem. Biol., 22, 251-261. https://doi.org/10.1016/j.chembiol.2014.12.012.

27. Bury P. D. S., Huang F., Li, S., Sun Y., Leadlay P. F., Dias M. V. B. (2017). Structural basis of the selectivity of GenN, an aminoglycoside N-methyltransferase involved in gentamicin biosynthesis. ACS Chem. Biol., 12, 2779-2787. https://doi.org/10.1021/ acschembio.7b00466.

28. MacNeil D. J., Gewain K. M., Ruby C. L., Dezeny G., Gibbons P. H., MacNeil T. (1992). Analysis of Streptomyces avermitilis genes required for avermectin biosynthesis utilizing a novel integration vector. 
Gene., 111, 61-68. https://doi.org/10.1016/0378-1119(92)90603-M

\section{Figures}

A
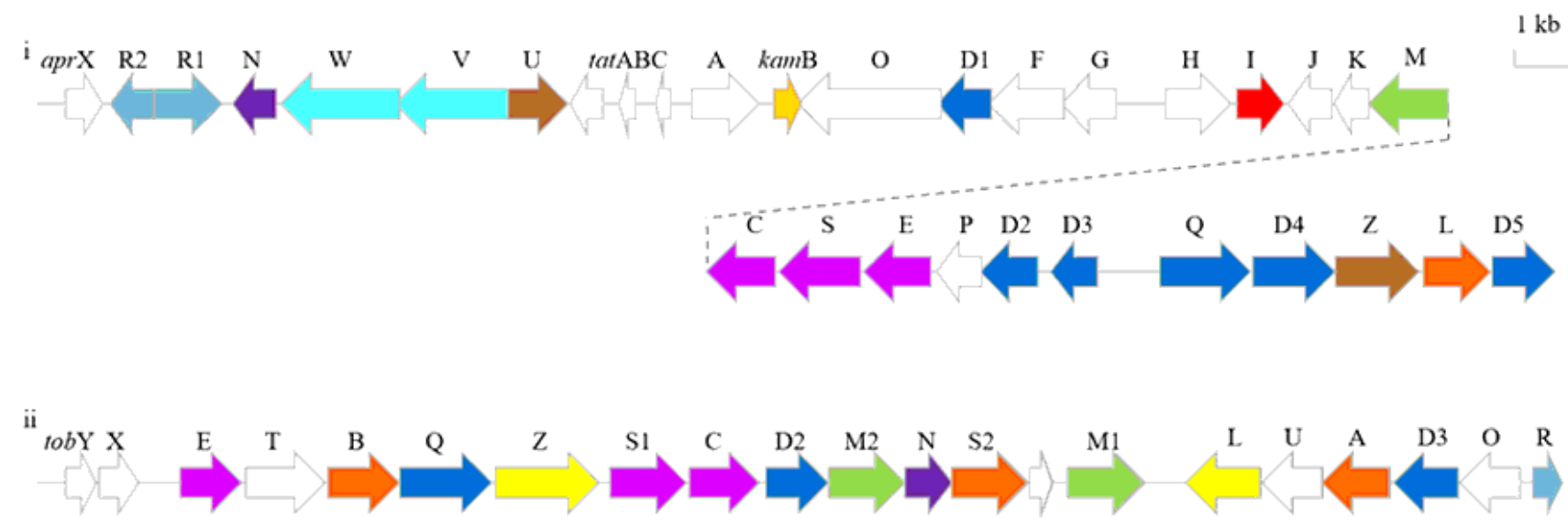
2-DOS synthetic gene
Methyltransferase gene
Regulatory gene
Resistance gene
Dehydrogenase gene
Deacetylase gene
Glycosyltransferase gene
Phosphatase gene
Aminotransferase gene
Carbamoyl-related gene
$A B C$-type exporter gene
Unknow

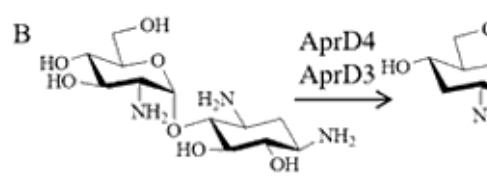

paromamine
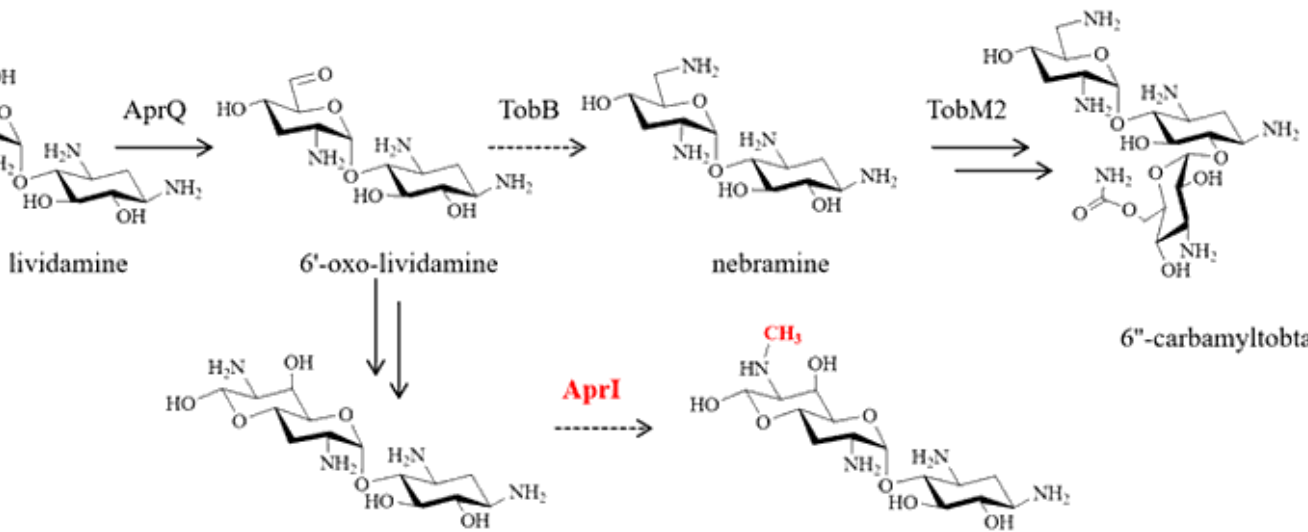

nebramine

6"-carbamyltobtamycin (5)

$$
\text { lividamine }
$$

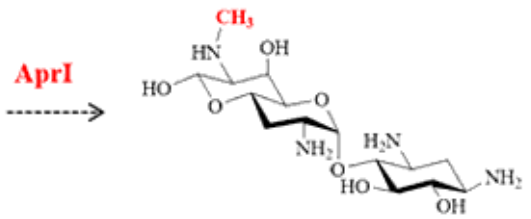

demethyl-aprosamine (4)

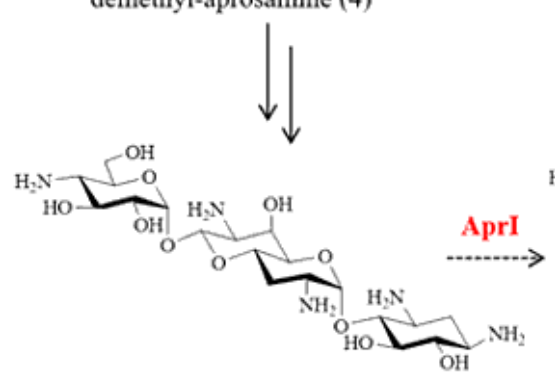

demethyl-apramycin (2) aprosamine (3)
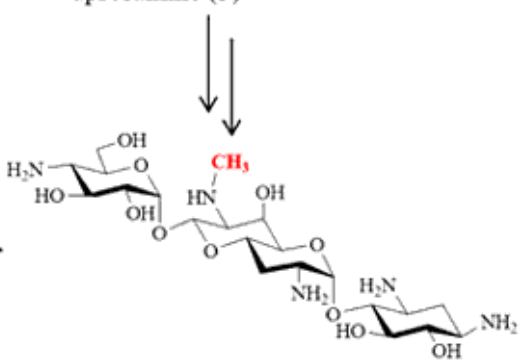

apramycin (1)

\section{Figure 1}

Apramycin biosynthetic gene cluster, tobramycin biosynthetic gene cluster and proposed apramycin biosynthetic pathway. (A) Apramycin biosynthetic gene cluster and tobramycin biosynthetic gene cluster. (B) Proposed apramycin biosynthetic pathway. 

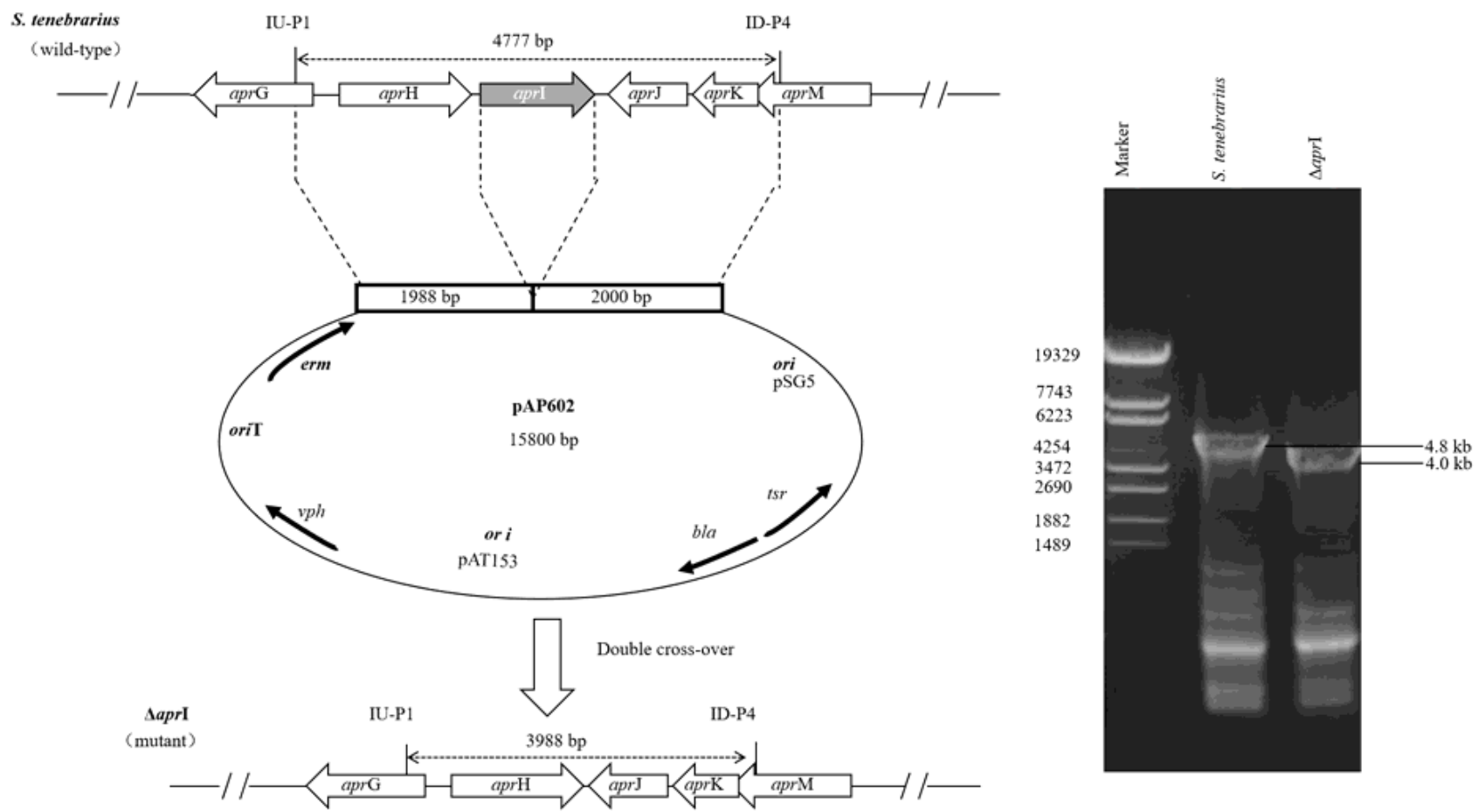

C

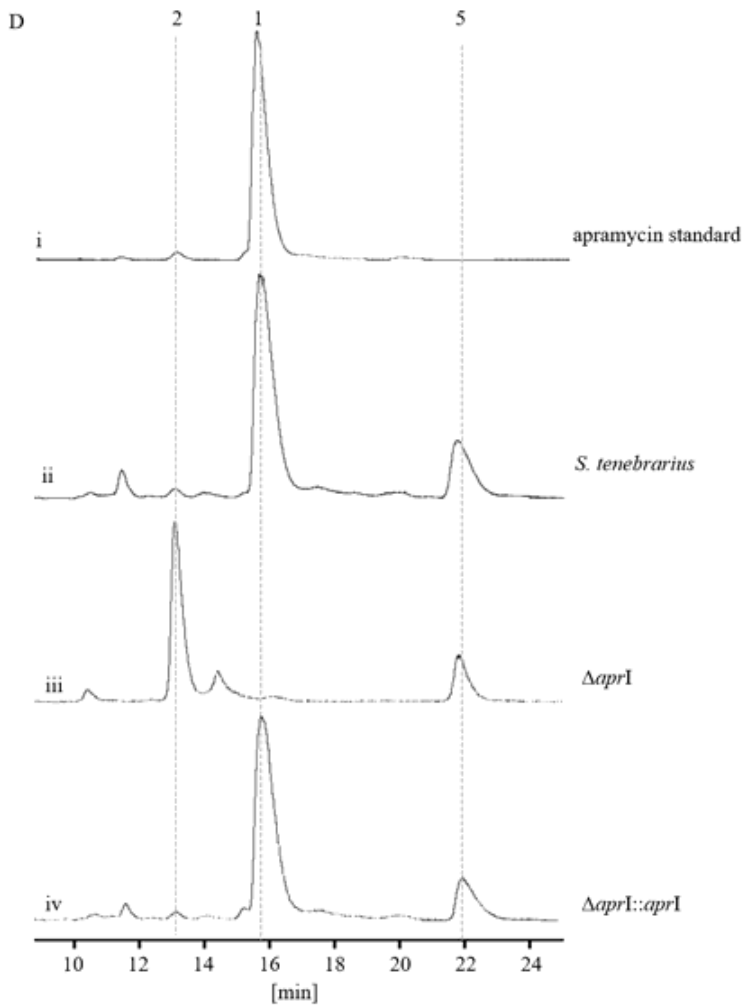

Figure 2

Identification of Aprl as the methyltransferase for 7'-N methylation. (A) Schematic representation of the aprl deletion. (B) Verification of $\triangle$ aprl mutant by PCR. PCR amplification with wild-type strain chromosome generated a $4.8 \mathrm{~kb}$ fragment, and $\Delta$ aprl strain chromosome generated a $4.0 \mathrm{~kb}$ fragment. (C) The analysis of products by TLC from wild-type S. tenebrarius and the $\triangle$ aprl. (D) HPLC analysis was 
performed by using an evaporative light-scattering detector (ELSD); (i) apramycin standard, (ii) wild-type S. tenebrarius, (iii) $\Delta$ aprl, and (iv) $\Delta$ aprl containing an aprl-expressing plasmid.
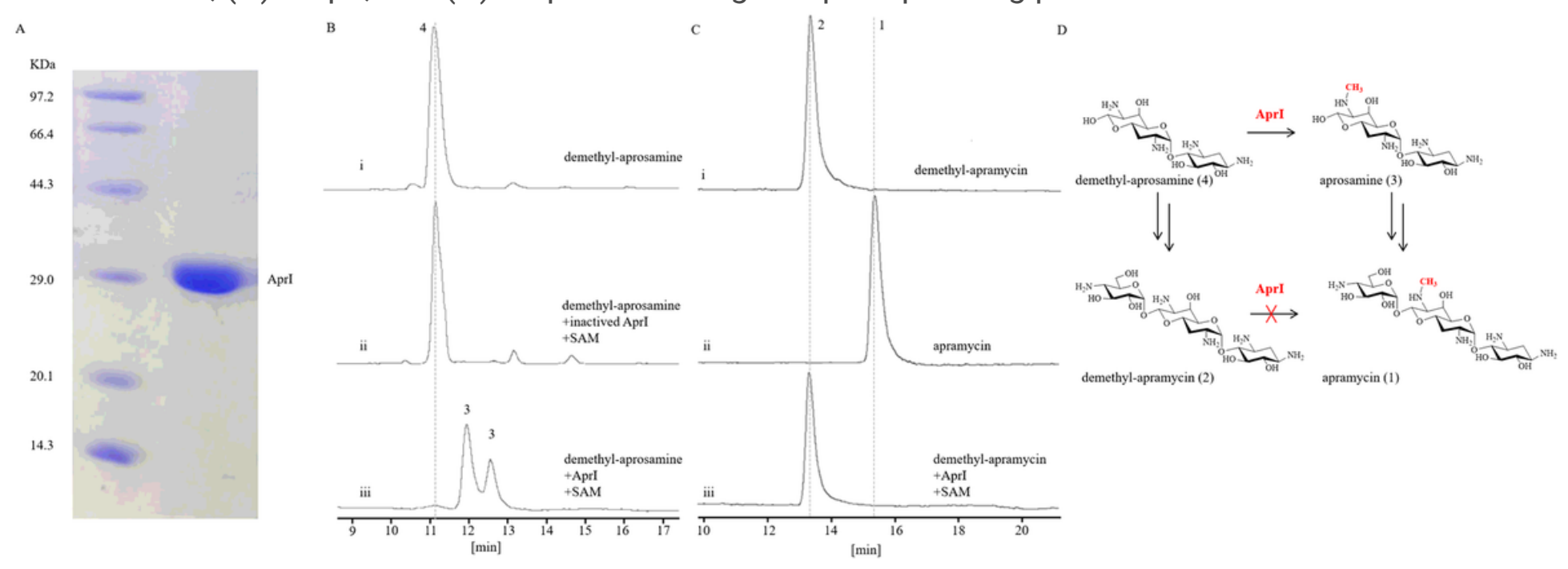

\section{Figure 3}

Characterization of Aprl as a SAM-dependent methyltransferase. (A) SDS-PAGE analysis of Aprl. (B) HPLC-ELSD analysis of the conversion of demethyl-aprosamine by Aprl in vitro; (i) demethyl-aprosamine, (ii) control reaction in which Aprl was omitted, and (iii) Aprl reaction with demethyl-aprosamine and SAM, Aprl convert demethyl-aprosamine into aprosamine. (C) HPLC-ELSD analysis of the conversion of demethyl-apramycin by Aprl in vitro. (i) demethyl-apramycin, (ii) apramycin, and (iii) Aprl reaction with demethyl-apramycin and SAM, Aprl cannot convert demethyl-apramycin into apramycin. (D) The 7'-N position methylation biosynthetic route of apramycin. 
A

\section{S. tenebrarius}

(wild-type)

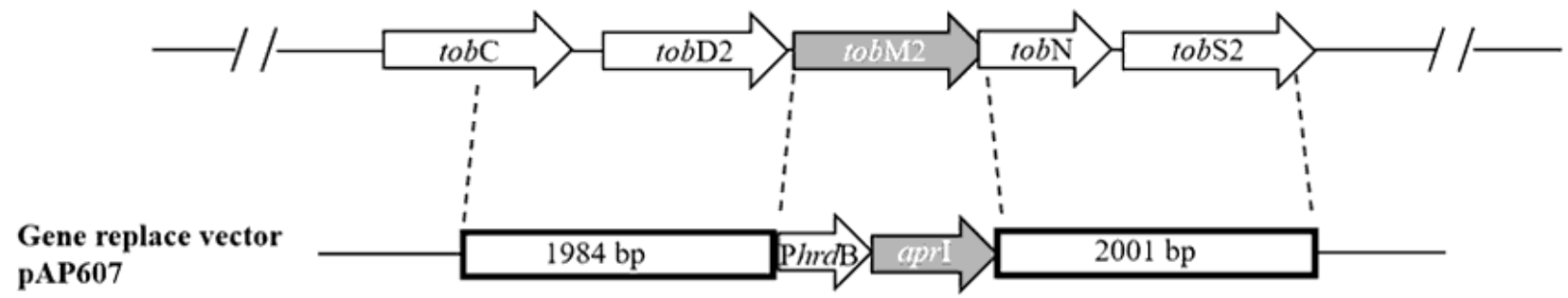

\section{S. tenebrarius IB}

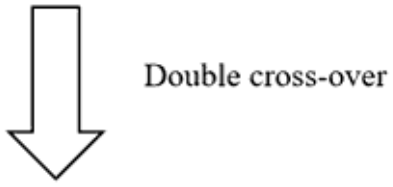

(mutant)

B

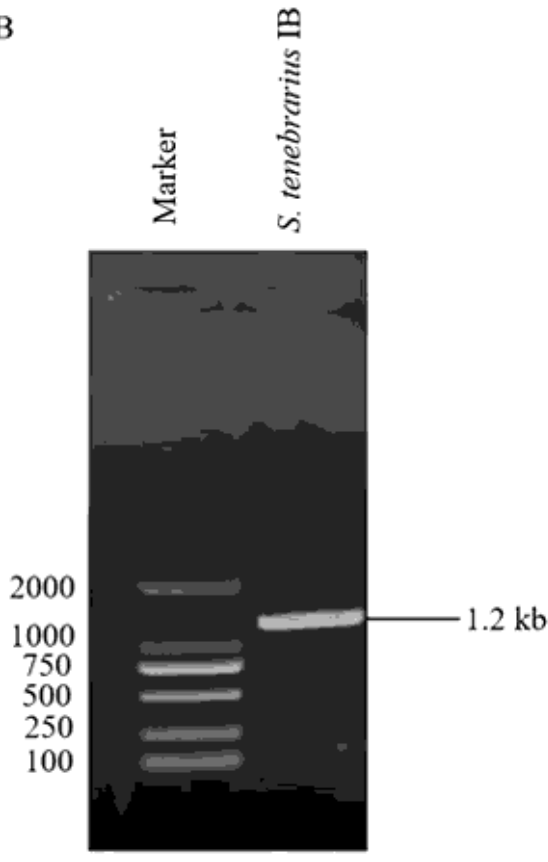

C

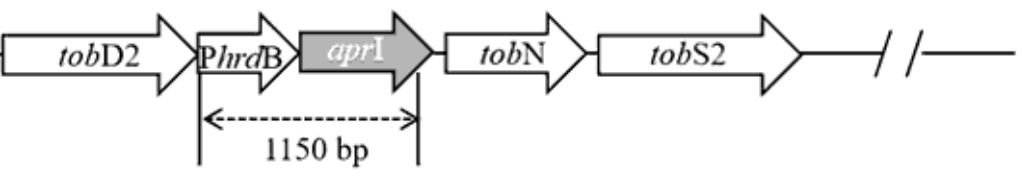

PhrdB-up

IB-P3

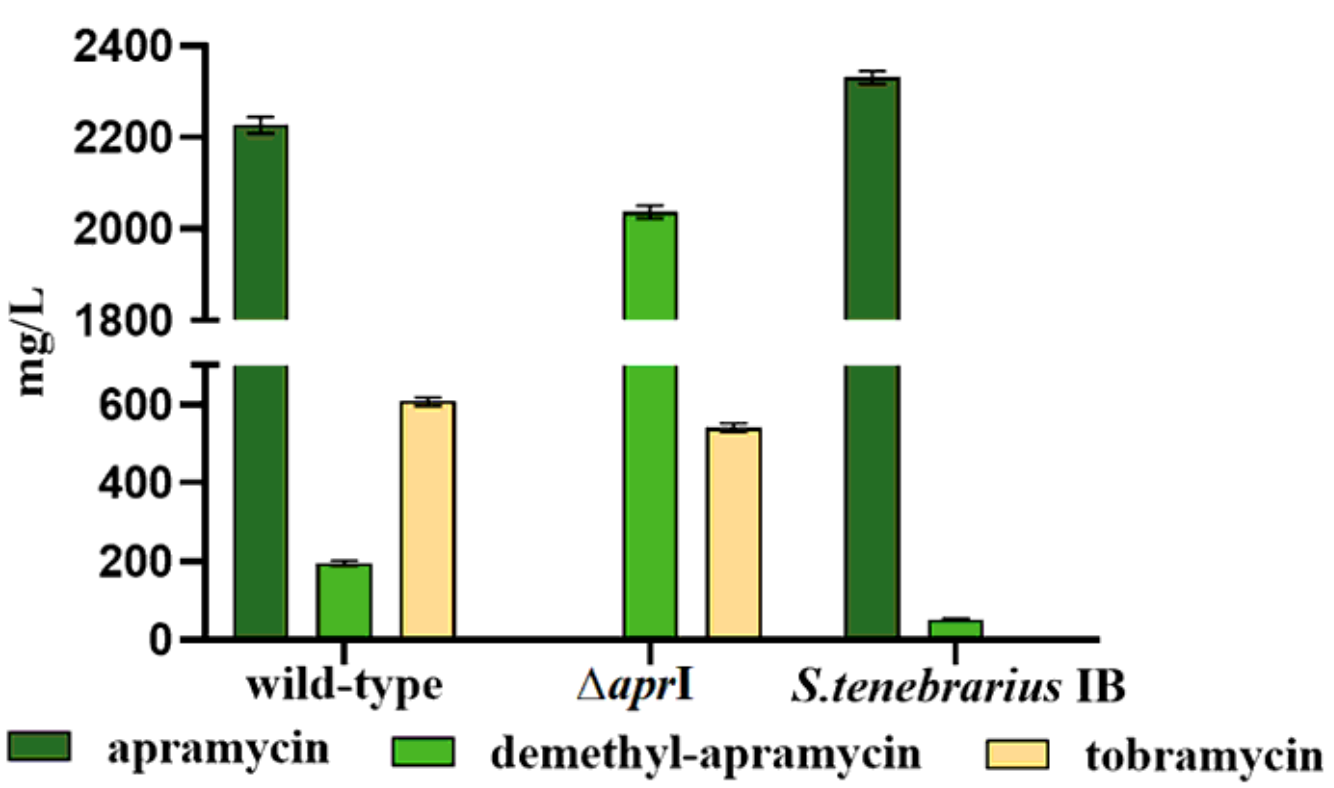

Figure 4

Construction and confirmation of the aprl overexpressing strain S. tenebrarius IB. (A) Schematic representation of the $S$. tenebrarius IB construction via homologous recombination. (B) Verifification of $S$. tenebrarius IB homologous recombination events. Primers PhrdB-up and IB-P3 were used and PCR amplifification showed that $\mathrm{S}$. tenebrarius IB had a $1.2 \mathrm{~kb}$ fragment. (C) Analysis of secondary metabolite yields.

\section{Supplementary Files}


This is a list of supplementary files associated with this preprint. Click to download.

- FIGS1.tif

- FIGS2.tif

- FIGS3.tif

- FIGS4.tif

- FIGS5.tif

- FIGS6.tif

- Tables1.pdf

- Tables2.pdf

- Tables3.pdf

- Tables4.pdf

- Tables5.pdf

- Tables6.pdf 